\title{
Fever or not fever - that's the question: A cohort study of simultaneously measured rectal and ear temperatures in febrile patients with suspected infection
}

\author{
Märta Sund Levander, Pia Tingström \\ Division of Nursing Sciences, Department of Medical and Health Sciences, Linköping University, Linköping, Sweden
}

Received: October 3, 2017

DOI: $10.5430 /$ cns.v6n2p47
Accepted: December 11, 2017 Online Published: December 18, 2017

URL: https://doi.org/10.5430/cns.v6n2p47

\begin{abstract}
Objective: To study how ear and rectal body temperatures relate to each other over time in febrile patients.

Methods: Descriptive cohort study with repeated measurements. The setting was a Unit for Infectious Diseases at a county hospital in Sweden. Patients, $\geq 18$ years, admitted for suspected infection and with a rectal or ear temperature of $\geq 37.5^{\circ} \mathrm{C}$ were invited. 16 females and 24 men, 19 to 94 years were included. Ear and rectal temperature was measured simultaneously every two hours for one day.

Results: Mean rectal temperature was higher, compared to both ear sites. Ninety-five percent of the differences between the rectal and ear sites were within $0.6^{\circ} \mathrm{C}$ to $1.1^{\circ} \mathrm{C}$. Changes in rectal temperature were smaller and slower than in ear temperature, especially when patients were given temperature-lowering drugs.

Conclusions: Adjustments from one temperature site to another is a risk of diagnostic error affecting clinical decision-making. Ear temperature reacts faster than the rectal site to body temperature changes and antipyretics, and is therefore more reliable in the assessment of the patient's condition. Traditional paradigm for temperature measurement and assessment needs to be replaced with evidence-based science to improve patient safety.
\end{abstract}

Key Words: Assessment, Body temperature, Clinical decision-making, Evidence-based practice, Fever, Nursing

\section{INTRODUCTION}

Evaluation of body temperature as a vital parameter for assessing the presence of fever still has great impact on medical diagnosis, laboratory test ordered, and decisions when infection is suspected. For example, fever is the main complaint in approximately $30 \%$ of parents consulting paediatricians. ${ }^{[1-3]}$ In clinical practice, the reading of body temperature is often compared and automatically adjusted by the device to another reference temperature, without the health care provider being aware of the adjustment. These adjustments, made by the manufacturers, vary considerably. ${ }^{[4-8]}$ However, Ring et al. ${ }^{[9]}$ emphasized the existence of not one, but several, core body temperatures dependent on temperature gradients within the body. These gradients also vary between individuals. ${ }^{[10]}$ Hence, there is no evidence of a $\mathrm{k}$-factor that converts and equates the temperatures measured at various sites. ${ }^{[10-15]}$ Nevertheless, it is still the rule rather than the exception to adjust and compare different sites, often based on the as-

\footnotetext{
*Correspondence: Märta Sund Levander; Email: martha.sund-levander@liu.se; Address: Division of Nursing Sciences, Department of Medical and Health Sciences, Linköping University, Building 511, Floor 14, Campus US, SE-58183 Linköping, Sweden. 
sumption that the rectal site is the most reliable and accurate site for body temperature measurement. ${ }^{[16-18]}$ This paper focuses on repeated simultaneously measured rectal and ear body temperature in febrile patients, in order to highlight and discuss the consequences of this practice.

The definition of normal body temperature as approximately $37^{\circ} \mathrm{C}$ and fever as $38^{\circ} \mathrm{C}$ was formulated in the middle of the $19^{\text {th }}$ century by the German physician Wunderlich. ${ }^{[19,20]}$ This was based on measurements in the axilla, which only assess skin and not core temperature. ${ }^{[21,22]}$ Although Wunderlich suggested a range and also discussed diurnal rhythm and differences between genders, fixed values are used in practice. Also, Mackowiak et al. ${ }^{[23]}$ showed that the thermometer used at that time measured $1.4^{\circ} \mathrm{C}$ to $2.2^{\circ} \mathrm{C}$ higher compared to modern digital devices. Today it is generally accepted that body temperature is a variation rather than a fixed temperature. ${ }^{[24]}$ As body temperature varies, it is reasonable to assume that the same applies to ${ }^{\circ} \mathrm{C}$ in fever ${ }^{[25]}$ In spite of this, normal body temperature defined as $37^{\circ} \mathrm{C}$ and fever as $\geq 38^{\circ} \mathrm{C}$ still remains the prevailing norm and paradigm. The large variation in normal body temperature creates confusion clinically when assessing whether a patient is febrile or not. ${ }^{[14,24]}$ Assessing body temperature is one of the most common data collected for clinical decision-making. This can be done either by the healthcare providers measuring the temperature themselves or by retrieving the information from the patient, next of kin or nursing assistants (NA). An earlier study revealed that when NAs deemed residents in nursing homes to be ill, they exaggerated the body temperature to make the nurse or physician take action. This was due to their beliefs that the elderly patient could be feverish even if they did not reach $38^{\circ} \mathrm{C} .{ }^{[26]}$ This indicates that the assumed norm is not always sufficient for professional judgement of patients' symptoms.

The pulmonary artery temperature is usually defined as core temperature, ${ }^{[10,21]}$ but in clinical practice the rectal site has been considered to estimate the true body temperature. Hence, oral and axillary sites have traditionally been adjusted to the rectal site by adding $0.3^{\circ} \mathrm{C}$ and $0.5^{\circ} \mathrm{C}$, respectively. ${ }^{[14]}$ The infrared ear thermometer (IRED) has been used in clinical practice for about 20 years. The IRED can be set to the actual measured temperature (direct/ear mode), but is more often adjusted to oral, rectal or PA temperature. ${ }^{[11]}$ However, these built-in adjustments are based on the manufacturer's unpublished estimations, and differ significantly. ${ }^{[4-8]}$

Systematic reviews ${ }^{[27,28]}$ and clinical trials have provided strong evidence that body temperature, measured at the rectal, oral, axillary and ear sites varies considerably between as well as within individuals. ${ }^{[10,29]}$ One study ${ }^{[10]}$ reported a temperature difference of $-0.7^{\circ} \mathrm{C}$ to $+2.8^{\circ} \mathrm{C}$ between the rectal 48 (reference temperature) and ear sites in healthy individuals. For the rectal - axillary and rectal - oral sites, the corresponding figures were $-1.4^{\circ} \mathrm{C}$ to $+2.3^{\circ} \mathrm{C}$, and $-1.5^{\circ} \mathrm{C}$ to $+2.3^{\circ} \mathrm{C}$, respectively. The results also indicated that the higher the rectal temperature, the larger the difference to other sites, which might have significant importance in febrile patients. The aim of the present study was to study how ear and rectal body temperatures relate to each other over time in febrile hospitalized patients with suspected infection.

\section{MethodS}

\subsection{Design and setting}

The study has a descriptive cohort design with repeated measurements. Data was collected during February 2012 to February 2013 at the Unit for Infectious Diseases at a county hospital in southern Sweden.

\subsection{Participants}

All patients aged 18 years or above, admitted to the infection clinic for suspected infection, diagnosed according to ICD criteria and assessed at admission with a rectal or ear temperature of $\geq 37.5^{\circ} \mathrm{C}$ were invited to participate. Patients with rectal malignity, terminal care, or diarrhoea were excluded. With an expected mean difference of $0.7^{\circ} \mathrm{C}$ and $1.5^{\circ} \mathrm{C}$ standard deviation between rectal and ear body temperature, ${ }^{[10]}$ power 0.80 and $p<.05$, the estimated sample needed was 37 individuals. Of 93 potentially eligible patients, 79 met the inclusion criteria. Forty-two patients gave informed consent to participate, of whom two patients discontinued participation. Hence, the final sample consisted of 40 patients, 16 women and 24 men, aged 19 to 94 years, admitted to the infection clinic for suspected infection.

\subsection{Data collection}

At admission, the patient or next of kin was given information and an invitation to participate by a registered nurse (RN). After providing informed consent, rectal and ear body temperature in both ears were measured simultaneously, i.e. ear and rectal measurements were performed directly consecutive, at 06:00-08:00 a.m. - 10:00-12:00 a.m., and 14:00-16:00 p.m -18:00-20:00 p.m. the next day. Measurements were conducted by RNs or NAs, all of them well experienced with the measurement as both techniques are routine at the hospital. To enhance measurement accuracy, one of the authors (MSL) before the study started, instructed healthcare providers, and the patient protocol stated that before measuring with the ear thermometer it was crucial to make sure the lens was clean, to replace probe protection between measurements, to wait 10 minutes if the patient was lying on the ear, and to note the actual reading without making any adjustments. Background data, i.e., gender, age, diagnosis and antibiotic 
treatment according to medical records, and drugs lowering temperature in fever, that is paracetamol, was noted in the specific study patient protocol.

\subsection{Measurements of body temperature}

Rectal temperature was measured with electronic devices (MC-638, Omron Health Care Europe BV, Täby, Sweden), and ear temperatures with IRED thermometers (Genius 2, Medtronic, Boston, MA, USA). The ear thermometer was set to the ear mode, that is, no adjustments to another site were done, and calibrated according to standard procedure by the manufacturer, using an infrared blackbody (IR-3000, Thermoscan, Inc.) before the study. All thermometers reported temperatures within $0.1^{\circ} \mathrm{C}$ of the reference temperature at $37^{\circ} \mathrm{C}$ and $40^{\circ} \mathrm{C}$, according to the ISO standard. ${ }^{[30]}$ The rectal thermometers were calibrated in a water bath at the county hospital's medical-technical department. The ear was the routine site for measuring body temperature at the county hospital where the study was performed.

\subsection{Ethical considerations}

Data was noted in individually coded protocols and in computer files. All data collected was anonymous, both on paper and in the computer. Included patients gave informed consent and could withdraw from the study at any time, without giving a reason. The study was approved by the Ethical Review Board at Linköping University (2011/13-31).

\subsection{Data analysis}

Data was analysed with proportions, $\mathrm{m} \pm$ standard deviation $(S D)$ and $95 \%$ confidence interval, and Student's paired $t$ test for comparison of the differences between simultaneous rectal and ear temperatures. All eligible measurements were included in the analysis.

\section{RESUlts}

Of the 40 included patients, 10 were admitted for fever of unknown origin, 7 for pneumonia, 6 for pyelonephritis/urinary tract infection, 6 for erysipelas/soft tissue infection, 5 for septicaemia, 4 for influenza, 1 for sinusitis, and 1 for dengue fever. Thirty-one was prescribed antibiotics at inclusion. Paracetamol $1 \mathrm{G}$ was administrated 4 times daily to 15 patients, and when needed to 15 patients (see Figures 1 to 3 ). Four did not receive paracetamol and in 6 patients data are missing. In 34 patients, the measurements were repeated every two hours for one day. In 6 patients, all scheduled measurements were not completed as 5 patients were discharged, and one patient found it troublesome to continuing measure rectal temperature.

Table 1. Simultaneously measurements, with two hours interval during day-time, of rectal and ear body temperature in 40 patients with infectious diseases

\begin{tabular}{lllll}
\hline Time & $\mathbf{n}=\mathbf{4 0}$ & $\begin{array}{l}\text { Right ear } \\
\mathbf{m} \pm \boldsymbol{S D}\left({ }^{\circ} \mathbf{C}\right)\end{array}$ & $\begin{array}{l}\text { Left ear } \\
\mathbf{m} \pm \boldsymbol{S D}\left({ }^{\circ} \mathbf{C}\right)\end{array}$ & $\begin{array}{l}\text { Rectal } \\
\mathbf{m} \pm \boldsymbol{S D}\left({ }^{\circ} \mathbf{C}\right)\end{array}$ \\
\hline 06 & 40 & $36.9 \pm 0.8$ & $36.8 \pm 0.8$ & $37.7 \pm 0.8^{* * * \# \# \#}$ \\
08 & 39 & $36.9 \pm 0.8$ & $36.8 \pm 0.8$ & $37.7 \pm 0.7^{* * * \# \#}$ \\
10 & 40 & $36.8 \pm 0.7$ & $36.7 \pm 0.7$ & $37.6 \pm 0.6^{* * * \# \#}$ \\
12 & 38 & $36.7 \pm 0.6$ & $36.7 \pm 0.7$ & $37.6 \pm 0.7^{* * * \# \# \#}$ \\
14 & 34 & $36.8 \pm 0.6$ & $36.8 \pm 0.7$ & $37.6 \pm 0.7^{* * * \# \#}$ \\
16 & 34 & $36.8 \pm 0.7$ & $36.8 \pm 0.7$ & $37.7 \pm 0.6^{* * * \# \#}$ \\
18 & 34 & $36.8 \pm 0.8$ & $36.8 \pm 0.7$ & $37.7 \pm 0.7^{* * * \# \#}$ \\
20 & 34 & $36.9 \pm 0.7$ & $36.9 \pm 0.7$ & $37.7 \pm 0.7^{* * * \# \#}$ \\
\hline
\end{tabular}

Note. Student's paired $t$-test; ${ }^{* * *} p<.001$ when comparing rectal versus right ear temperatures; ${ }^{\# \#} p<.001$ when comparing rectal versus left ear temperatures

The mean rectal temperature was constantly higher compared to both ear sites, $p<.001$ (see Table 1). Ninety-five percent of the difference between the rectal and ear sites was within $0.6^{\circ} \mathrm{C}$ to $1.1^{\circ} \mathrm{C}, p<.001$ (see Table 2).

Rectal and ear temperature curves constantly followed each other (see Figure 1). The decrease and increase in rectal temperature were smaller than in ear temperature. The rectal temperature could remain high, while the ear temperature decreased (see Figure 2). There was a slower change in rectal temperature compared to the ear sites, especially when Published by Sciedu Press patients were treated with temperature-lowering drugs (see Figure 3). The mean difference between right and left ear measurements were not significant; within $-0.2^{\circ} \mathrm{C}$ to $+0.3^{\circ} \mathrm{C}$ (see Table 3).

\section{Discussion}

This study illustrates simultaneously measured rectal and ear body temperatures over time in febrile patients with suspected infection. The temperature curves in Figure 1 clearly show that the temperatures correlate, i.e., the curves follow 
each other, that the rectal temperature is almost constantly higher than the ear temperature. Rectal temperature is in general higher than at other places, ${ }^{[31,32]}$ due to the low blood flow and high isolation of the area, leading to a low heat loss. ${ }^{[33]}$ Also, the heat-producing activity of micro-organisms in faeces influences the reading. ${ }^{[34]}$ In line with previous research, ${ }^{[10]}$ it is also obvious that the difference between rectal and ear temperatures differs between individuals, strength- ening that exact ${ }^{\circ} \mathrm{C}$ for adjustments between sites does not exist. ${ }^{[10-14]}$ Hence, the same measurement site should be used, without adjusting to another reference site. Added to a constantly higher rectal temperature, it is also evident from Figures 2 and 3 that there is a smaller increase and decrease, and a slower change in rectal temperature, compared to the ear temperature.

Table 2. Difference between rectal and right ear, and rectal and left ear body temperature, measured simultaneously with two hours interval during day-time, in 40 patients with infectious diseases

\begin{tabular}{|c|c|c|c|c|c|c|c|c|}
\hline \multirow{3}{*}{ Time } & \multicolumn{4}{|c|}{ Difference rectal and right ear site } & \multicolumn{4}{|c|}{ Difference rectal and left ear site } \\
\hline & \multirow{2}{*}{$\mathrm{n}=\mathbf{4 0}$} & \multirow{2}{*}{ Mean $\pm S D\left({ }^{\circ} \mathrm{C}\right)$} & \multicolumn{2}{|c|}{$95 \% \mathrm{CI}^{\#}$ of the difference } & \multirow{2}{*}{$\mathrm{n}=\mathbf{4 0}$} & \multirow{2}{*}{ mean $\pm S D\left({ }^{\circ} \mathrm{C}\right)$} & \multicolumn{2}{|c|}{$95 \% \mathrm{CI}^{\#}$ of the difference } \\
\hline & & & Lower $\left({ }^{\circ} \mathbf{C}\right)$ & Higher $\left({ }^{\circ} \mathbf{C}\right)$ & & & Lower $\left({ }^{\circ} \mathbf{C}\right)$ & Higher $\left({ }^{\circ} \mathbf{C}\right)$ \\
\hline 06 & 37 & $0.8 \pm 0.5^{* * * *}$ & 0.6 & 1.0 & 36 & $0.8 \pm 0.6^{* * * *}$ & 0.6 & 1.0 \\
\hline 08 & 39 & $0.9 \pm 0.5^{* * *}$ & 0.8 & 1.1 & 38 & $1.0 \pm 0.5^{* * *}$ & 0.8 & 1.1 \\
\hline 10 & 39 & $0.8 \pm 0.5^{* * *}$ & 0.6 & 1.0 & 37 & $0.9 \pm 0.5^{* * *}$ & 0.7 & 1.1 \\
\hline 12 & 35 & $0.9 \pm 0.5^{* * *}$ & 0.8 & 1.1 & 35 & $0.9 \pm 0.5^{* * *}$ & 0.8 & 1.1 \\
\hline 14 & 32 & $0.8 \pm 0.7^{* * *}$ & 0.5 & 1.0 & 31 & $0.8 \pm 0.6^{* * *}$ & 0.6 & 1.0 \\
\hline 16 & 33 & $0.9 \pm 0.4^{* * *}$ & 0.7 & 1.0 & 32 & $0.9 \pm 0.5^{* * *}$ & 0.7 & 1.1 \\
\hline 18 & 33 & $0.8 \pm 0.6^{* * *}$ & 0.7 & 1.1 & 32 & $0.9 \pm 0.5^{* * *}$ & 0.7 & 1.1 \\
\hline 20 & 32 & $0.8 \pm 0.5^{* * *}$ & 0.6 & 1.0 & 30 & $0.8 \pm 0.7^{* * * *}$ & 0.5 & 1.0 \\
\hline
\end{tabular}

Note. ${ }^{\#} \mathrm{CI}=$ Confidence interval; Student's paired $t$-test; ${ }^{* * *} p<.001$
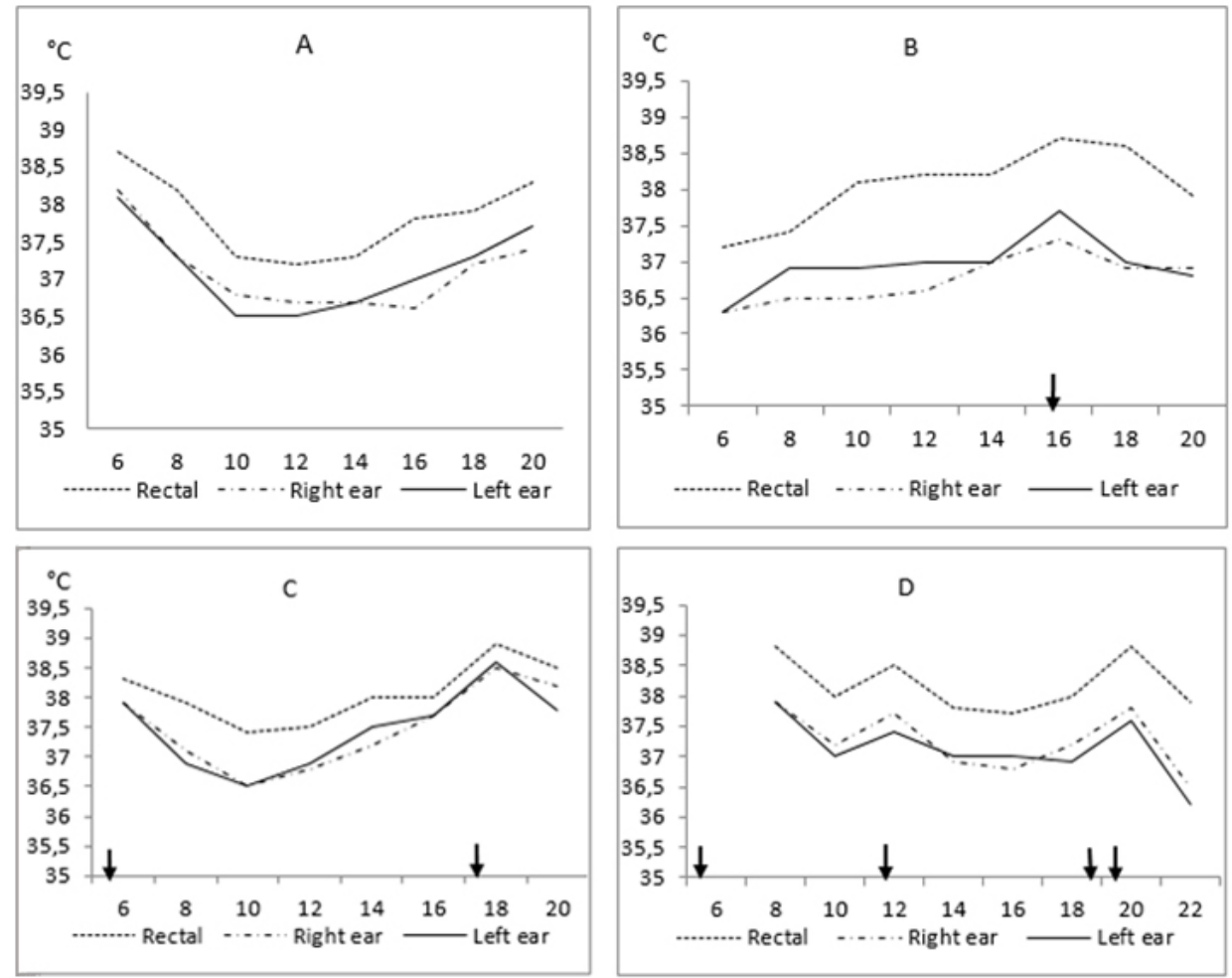

Figure 1. Illustration of simultaneously measured rectal and ear body temperature in patients with infectious disease. Black arrows illustrate administration of paracetamol before measurement.

A. Case 67. Women, age 86, cared for erysipelas and septicemia; B. Case 58. Man, age 60, cared for fever of unknown origin; C. Case 52. Woman, age unknown, cared for fever of unknown origin; D. Case 26. Man, age 20, cared for suspected meningitis. 

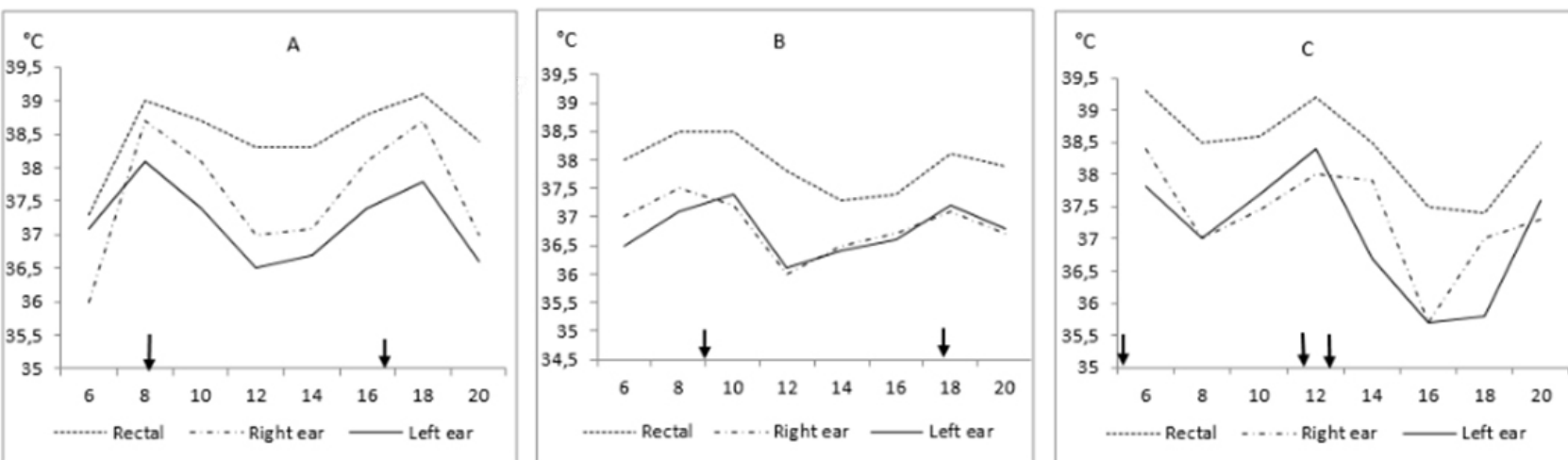

Figure 2. Illustration of how rectal temperature changes less, compared to ear temperature changes. Simultaneously measurements of rectal, right and left ear body temperature in patients with infectious disease. Black arrows illustrate administration of paracetamol before measurement.

A. Case 60. Woman, age 64, cared for pneumonia. Between 8 and 12, ear temperatures decrease $1.5^{\circ} \mathrm{C}$ and $1.6^{\circ} \mathrm{C}$, and rectal temperature $0.7^{\circ} \mathrm{C} ; \mathrm{B}$. Case 55. Man, age 75, cared for erysipelas. Ear temperature decrease $1.2^{\circ} \mathrm{C}$ and rectal temperature $0.7^{\circ} \mathrm{C}$ between 10 and 12; C. Case 12. Man, age 51, cared for erysipelas. Ear temperature decrease $2.3^{\circ} \mathrm{C}$ and rectal temperature $1.7^{\circ} \mathrm{C}$ between 12 and 14. Between 16 and 20 ear temperature rise $1.6^{\circ} \mathrm{C}$ and rectal temperature $1^{\circ} \mathrm{C}$.
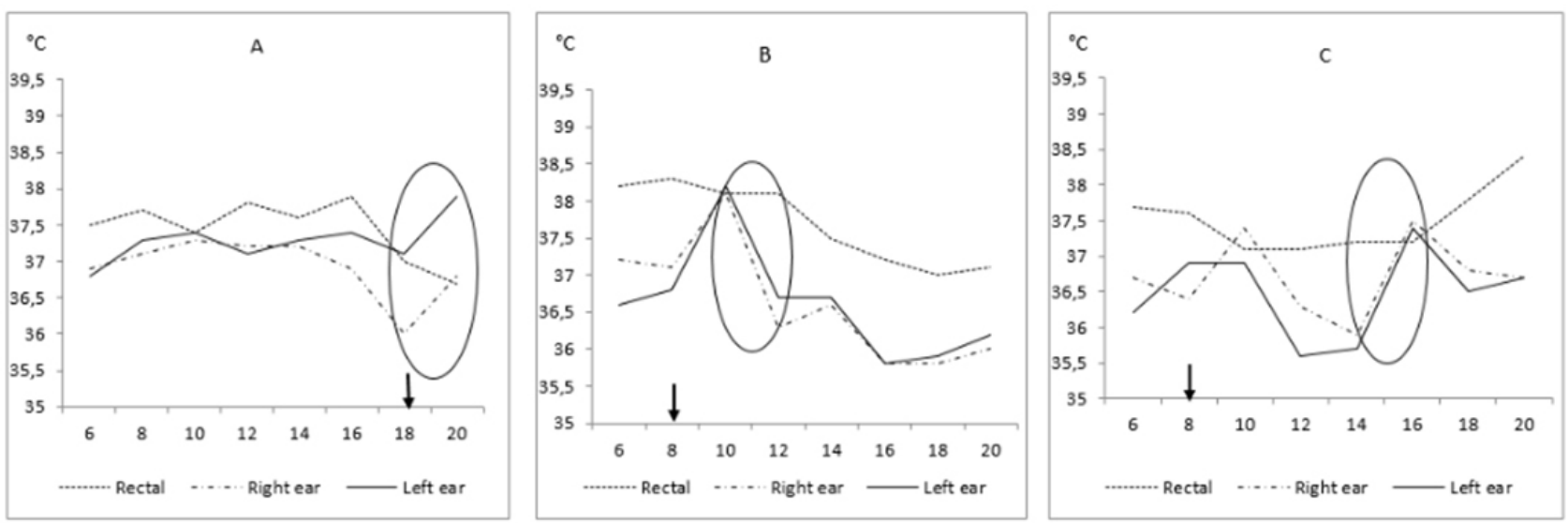

Figure 3. Illustration of rectal lag times in body temperature changes. Simultaneously measurements of rectal, right and left ear body temperature in patients with infectious disease. Black arrows illustrate administration of paracetamol before measurement. Ovals illustrate the delay in change in rectal temperature.

A. Case 65. Woman, age 73, cared for pneumonia; B. Case 64. Man, age 64, cared for urosepsis; C. Case 13. Man, age 70, cared for pyelonephritis.

Table 3. Mean difference between right and left ear temperatures, measured simultaneously with two hours interval during day-time, in 40 patients with infectious diseases

\begin{tabular}{lllll}
\hline \multirow{2}{*}{ Time } & $\mathbf{n}=\mathbf{4 0}$ & $\begin{array}{l}\text { Difference } \\
\text { mean } \pm \boldsymbol{S D}\left({ }^{\circ} \mathbf{C}\right)\end{array}$ & \multicolumn{2}{c}{$\begin{array}{c}\mathbf{9 5 \%} \text { confidence interval of } \\
\text { the difference }\end{array}$} \\
\cline { 4 - 5 } & & & Lower $\left({ }^{\circ} \mathbf{C}\right)$ & Higher $\left({ }^{\circ} \mathbf{C}\right)$ \\
\hline 06 & 37 & $0.2 \pm 0.5$ & -0.1 & 0.3 \\
08 & 38 & $0.1 \pm 0.4$ & -0.1 & 0.2 \\
10 & 37 & $0.1 \pm 0.4$ & -0.0 & 0.3 \\
12 & 34 & $0.1 \pm 0.4$ & -0.1 & 0.2 \\
14 & 31 & $0.0 \pm 0.4$ & -0.1 & 0.2 \\
16 & 32 & $0.0 \pm 0.4$ & -0.1 & 0.2 \\
18 & 32 & $0.0 \pm 0.6$ & -0.2 & 0.2 \\
20 & 30 & $0.0 \pm 0.2$ & -0.2 & 0.1 \\
\hline
\end{tabular}

Published by Sciedu Press
A common reaction in clinical practice to elevated rectal temperature (fever) and simultaneous lower ear temperature (not fever) is that the rectal site is a reliable method to detect fever, whereas ear temperature is not. ${ }^{[35]}$ However, the different values genuinely reflect the fact that the set point temperature in the temperature centre of the hypothalamus has already been lowered in order to stimulate heat-generating mechanisms, but the temperature is not yet adjusted in the rectum. ${ }^{[36]}$ As illustrated in Figure 3, another explanation might be that the patient has received temperature lowering drugs that initially result in a lower ear than rectal temperature. ${ }^{[37]}$ In such situations there is a risk of overdose of paracetamol and similar drugs, which might lead to severe side effects and 
complications for the patient, especially in children. Of special concern is that physicians often advise the caregiver to alternate ibuprofen and paracetamol, in spite of the increased risk of overdosing and adverse effects. ${ }^{[1,38]}$

The explanation to the differences between the rectal and ear temperature changes is simply physiological. The temperature regulation process - from the neurons in hypothalamus reading and interpreting information until adjustments all over the body are made - takes time. The further away the site of measurement is from the hypothalamus, the longer time to adjust the temperature to the set point of the hypothalamus. Hence, there is a lag time for rectal temperature changes. ${ }^{[34]}$ This means that measuring ear temperature promotes the detection of changes in body temperature earlier than with rectal measurement, which thereby prevents unnecessary medication with antipyretics.

Since the days of Wunderlich, there has been a considerable development of the technology needed for accurate clinical thermometers and standards for quality assurance in the manufacturing process. ${ }^{[30]}$ Consequently, the technical accuracy is adequate. Beside advances in the technical aspects of thermometers, there has been progress in the clinical accuracy as well. This can be observed in the understanding of thermoregulation, in terms of the diurnal rhythm and the physiological mechanisms that maintain a stable and balanced internal environment, the role of female hormones, and immunological processes that influence body temperature in health and disease. ${ }^{[29]}$ Today, quality assurance and patient safety are also obligations within health care, which together with the demand for evidence-based decision-making now form the basis for ensuring good care ${ }^{[39]}$ However, even if the technical accuracy of measurements has greatly improved, the clinical accuracy is still not considered equally important for body temperature assessment. That is, differences between groups of individuals, such as gender and age are not considered, and adjusting and comparing different sites for body temperature measurement is the rule rather than the exception in clinical practice. ${ }^{[10-14]}$ In addition, considerable differences in body temperature between individuals as well as temperature gradients within the same individual are present in health ${ }^{[10]}$ as well as in fever. ${ }^{[25]}$

The public as well as care providers still use the term fever as if there was a joint memorandum of understanding on what constitutes fever, even though these views are really based on personal interpretations and experiences. Personal beliefs might be understandable for the public, but in health care, decision-making based on tradition rather than evidencebased science can lead to serious consequences for the patient. For example, in the frail and elderly, the consequences are delayed diagnosis, treatment and increased mortality. ${ }^{[0]}$ Another contributing factor influencing common beliefs about body temperature in health and disease is the conviction that it is a necessity to use cut-off limits for what is normal and abnormal in order to define physiological processes. These norms were established in the 1950s, described as the duty of physiology to define in quantitative terms the criteria of normality as the basis for the study and diagnosis of human disease. ${ }^{[41]}$ It is not unreasonable to assume that Wunderlish's nearly 200-year-old paradigm for defining normal temperature and fever has been even more consolidated during this time, without questioning the credibility of the definition.

Taken together, a great deal is known on how to improve reliability and accuracy in assessment of body temperature, from a technical as well as a physiological viewpoint. In light of evidence-based practice, it is of great importance to base the measurement and assessment of temperature on science rather than tradition or personal belief. The question is why there is such a focus on control of technical accuracy in terms of global standards, ${ }^{[30]}$ but not on clinical accuracy, such as inter- and intra- individual variations. A possible interpretation is that body temperature measurement is considered a trivial procedure performed by anyone, without requiring specific knowledge. Still, the results are of great significance for clinical decision-making. ${ }^{[26]}$ Now is the time to change the paradigm for body temperature measurement into evidencebased practice based on science, rather than tradition and non-reflected assumptions. That is, make no adjustments between sites for body temperature measurements. Instead of using predetermined, universal cut-off values, another way might be to consider the difference between the individual baseline body temperature and the measured reading, along with malaise, as temperature in fever. ${ }^{[29]}$

\section{Conclusions}

In conclusion, the arguement that adjustments from one temperature site to another do not give correct information for diagnosis, and hence is a risk of diagnostic error affecting the medical clinical decision-making is supported by this work and previous results. The lag time in rectal temperature changes should be considered as well. The ear temperature reacts faster than the rectal site to body temperature changes and antipyretics, and is therefore more reliable in the assessment of the patient's condition. The relevance for clinical practice is that the traditional, prevailing paradigm for temperature measurement and assessment needs to be replaced with evidence-based science to improve patient safety. This needs to be done in terms of accurate diagnosis and appropriate testing and treatment. Responsible for nursing, 
registered nurses are in a position to implement this into clinical practice.

Finally, there are some limitations to consider when interpreting the present results. First, data about chronic conditions and other diseases other than suspected infection was not documented, which might affect generalizability. Second, the presence of ear wax, which might lower ear temperature, was not controlled for. There was no difference between ear sites, however, which supports the impression that wax was not a significant problem. Third, several individuals performed the measurements, which might affect measurement accuracy. The ear site is hospital routine in the hospital, and the individual ear temperature curves followed each other, confirming good operator technique.

\section{SUMMARY STATEMENT}

What is already known about this topic:

In clinical practice, body temperature is often compared and adjusted to another reference temperature, e.g. adjustment of the ear temperature to the rectal site.
What this paper adds:

This study illustrates simultaneously measured rectal and ear body temperatures over time in febrile patients with suspected infection.

The implication of this paper:

Adjustments from one temperature site to another do not give correct information for diagnosis, and hence is a risk of diagnostic error affecting the medical clinical decision-making. The ear temperature reacts faster than the rectal site to body temperature changes and antipyretics.

\section{ACKNOWLEDGEMENTS}

Futurum, the Academy for Health and Disease, Jönköping County kindly supported the study financially.

We thank all participating patients and staff at the Department of Infectious Disease, particularly Elisabeth Gustavsson, for data collection and performance.

\section{CONFLicts OF InTEREST Disclosure}

The authors declare they have no conflicts of interest.

\section{REFERENCES}

[1] Dermi F, Sekreter O. Knowledge, attitudes and misconceptions of primary care physicians regarding fever in children: a cross sectional study. Ital J Paediatr. 2012; 38(40): 1-7.

[2] Hoover LA. AP report on the use of antipyretics for fever in children. Am Fam Physician. 2012; 1(85): 518-519.

[3] Walsh A, Edwards H, Courtny M, et al. Fever management: Paediatric nurses' knowledge, attitudes and influencing factors. Issues and Innovations in nursing Practice. J Adv Nurs. 2005; 49(5): 453464. PMid: 15713177. https://doi.org/10.1111/j.1365-264 8.2004.03318.x

[4] Shinozaki T, Deane R, Perkins FM. Infrared tympanic thermometer. Evaluation of a new clinical thermometer. Critical Care Medicine. 1988; 16: 148-150. PMid: 3342626. https://doi.org/10.1097/ 00003246-198802000-00011

[5] Terndrup TE. An appraisal of temperature assessment by infrared emission detection tympanic thermometry. Annals of Emergency Medicine. 1992; 21(12): 1483-1492. https://doi.org/10.101 6/S0196-0644(05) 80067-8

[6] Erickson RS, Kirklin SK. Comparison of ear-based, bladder, oral and axillary methods for core temperature measurement. Critical Care Medicine. 1993; 21(10): 1528-1534. https://doi.org/10.109 7/00003246-199310000-00022

[7] Brennan D, Falk J, Rothbrock S, et al. Reliability of infrared tympanic thermometry in the detection of rectal fever in children. Annals of Emergency Medicine. 1995; 25(1): 21-30. https://doi.org/ 10.1016/S0196-0644 (95) 70350-0

[8] Schmitz B, Bair N, Falk M, et al. A comparison of five methods of temperature measurement in febrile intensive care patients. American Journal of Critical Care. 1995; 4(4): 286-292. PMid: 7663592.
[9] Ring EFJ, Mcevoy H, Jungs A, et al. New standards for devices used for the measurement of human body temperature. Journal of Medical Engineering \& Technology. 2010; 34: 249-253. PMid: 20397848 https://doi.org/10.3109/03091901003663836

[10] Sund-Levander M, Grodzinsky E, Loyd D, et al. Error in body temperature assessment related to individual variation, measuring technique and equipment. International Journal of Nursing Practice. 2004; 10 : 216-223. PMid: 15461691. https://doi.org/10.1111/j.1440 $-172 \mathrm{X} .2004 .00483 . \mathrm{x}$

[11] Betta V, Cascetta F, Sepe D. An assessment of infrared tympanic thermometers for body temperature measurement. Physiological Measurement. 1997; 18: 215-225. PMid: 9290138. https://doi.org/ $10.1088 / 0967-3334 / 18 / 3 / 006$

[12] Erickson RT, Woo TM. Accuracy of infrared ear thermometry and traditional temperature methods in young children. Heart \& Lung. 1994; 23(3): 182-195.

[13] Konopad E, Kerr JR, Noseworthy T, et al. A comparison of oral, axillary, rectal and tympanic-membrane temperatures of intensive care patients with and without an oral endotracheal tube. Journal of Advanced Nursing. 1994; 20: 77-84. PMid: 7930131. https: //doi.org/10.1046/j.1365-2648.1994.20010077.x

[14] Sund-Levander M, Grodzinsky E. Time for a change to assess and evaluate body temperature in clinical practice. International Journal of Nursing Practice. 2009; 15: 241-249. PMid: 19703039. https://doi.org/10.1111/j.1440-172X.2009.01756.x

[15] Sund Levander M, Grodzinsky E. Variation in normal ear temperature. American Journal of the Medical Sciences. 2017. https: //doi.org/10.1016/j.amjms.2017.05.013

[16] Batra P, Goyal S. Comparison of rectal, axillary, tympanic, and temporal artery thermometry in the pediatric emergency room. Pe- 
diatr Emerg Care. 2013 Jul; 29(7): 877. PMid: 23823276. https : //doi.org/10.1097/PEC.0b013e31829ba48b

[17] Craig J, Lancaster G, Taylor S, et al. Infrared ear thermometry compared with rectal thermometry in children: a systematic review. The Lancet. 2002; 360: 603-609. https://doi.org/10.1016/S014 0-6736 (02) 09783-0

[18] Varney S, Manthey D, Culpepper V, et al. A comparison of oral, tympanic, and rectal temperature measurement in the elderly. The Journal of Emergency Medicine. 2001; 22(2): 153-157. https: //doi.org/10.1016/S0736-4679(01)00457-7

[19] Ivy AC. Comment: What is normal body temperature? Gastroenterology. 1945; 5: 326-329. PMid: 21007061.

[20] Wunderlich CA, Seguin E. Medical Thermometry and Human Temperature. New York: William Wood \& Co; 1871

[21] Mackowiak PA. Clinical thermometric measurements. In: Mackowiak PA, ed. Fever. Basic Mechanisms and Management. 2 ed. Philadelphia, New York: Lippincott Raven; 1997. 27-33 p.

[22] Metlay J, Schulz R, Li Y, et al. Influence of age on symptoms at presentation in patients with community-acquired pneumonia. Archives of Internal Medicine. 1997; 157(13): 1453-1459. PMid: 9224224. ht tps://doi.org/10.1001/archinte.1997.00440340089009

[23] Mackowiak PA, Worden G. Carl Reinhold August Wunderlich and the evolution of clinical thermometry. Clinical Infectious Diseases. 1994 18: 458-467. https://doi.org/10.1093/clinids/18.3.458

[24] Mackowiak PA, Wassermann SS. Physicians perceptions regarding body temperature in health and disease. Southern Medical Journal. 1995; 88(9): 934-938. https ://doi .org/10 .1097/00007611-1 99509000-00009

[25] Mackowiak PA. Fever's upper limit. In: Mackowiak PA, ed. Fever. Basic Mechanisms and Management. 2 ed. Philadelphia, New York: Lippincott Raven; 1997. 147-163 p.

[26] Sund-Levander M, Tingström P. Clinical decision making process of early nonspecific signs of infection in institutonalozed elderly persons: Experience of nursing assistants. Scandinavian Journal of Caring Sciences. 2012. PMid: 22536887.

[27] Sund-Levander M, Forsberg C, Wahren LK. Normal oral, rectal, tympanic and axillary body temperature in adult men and women: A systematic literature review. Scandinavian Journal of Caring Sciences. 2002; 16(2): 122-128. PMid: 12000664. https://doi.org/10.1 $046 / j \cdot 1471-6712.2002 .00069 \cdot x$

[28] Lu S, Leasure A, Dai Y. A systematic review of body temperature variations in older people. Journal of Clinical Nursing. 2010; 19(1-2): 4-16. PMid: 19886869. https://doi.org/10.1111/j.1365-2 702.2009.02945.x

[29] Grodzinsky E, Sund Levander M, eds. Assessment of fever. Physiology, immunology, measurement in clinical practice. Malmö: Gleerups; 2015.
[30] ISOISOISO. Medical electrical equipment_Part 2-56: Particular requirements för basic safety and essential performance of clinical thermometers for body temperature measurement. Vol ISO 80601-256: 2009: E. Switzerland.2014.

[31] Milewski A, Ferguson KL, Terndrup TE. Comparison of pulmonary artery, rectal and tympanic membrane temperatures in adult intensive care unit patients. Clinical Pediatrics. 1991; 4(Suppl): 13-16. PMid: 2029812. https://doi.org/10.1177/0009922891030004S05

[32] Zehner WJ, Terndrup TE. The impact of moderate ambient temperature variance on the relationship between oral, rectal, and tympanic membrane temperatures. Clinical Pediatrics. 1991; 4: 61-64. PMid: 2029823. https://doi.org/10.1177/0009922891030004S19

[33] Petersen M, Hauge H. Can training improve the results with infrared tympanic thermometers? Acta Anaesthesiologica Scandinavica. 1997; 41: 1066-1070. PMid: 9311408. https://doi.org/10 $.1111 / j .1399-6576.1997 . t b 04837 . x$

[34] Blatties C. Methods of temperature measurement. In: Blatties C, ed. Physiology and Pathophysiology of Temperature Regulation. Singapore: World Scientific Publishing Co. Pte. Ltd; 1998. 273-279 p.

[35] Niven D, Gaudet J, Laupland K, et al. Accuracy of peripheral thermometers for estimating temperature: a systematic review and metaanalysis. Ann Intern Med. 2015; 17(10): 768-777. PMid: 26571241. https://doi.org/10.7326/M15-1150

[36] Chamberlain JM, Torndrup TE, Alexander DT, et al. Determination of normal ear temperature with an infrared emission detection thermometer. Annals of Emergency Medicine. 1995; 25: 15-20. https://doi.org/10.1016/S0196-0644(95) 70349-7

[37] Mackowiak PA. Physiological rationale for suppression of fever. Clinical Infectious Diseases. 2000; 31(Suppl. 5): 185-189. PMid: 11113022. https://doi.org/10.1086/317511

[38] Chiappini E, Parretti A, Becherucci P, et al. Parental and medical knowledge and management of fever in Italian pre-school children. BMC Pediatr. 2012; 12(97). https ://doi .org/10.1186/1471-2 431-12-97

[39] National indicators for good care (Nationella indikationer för god vård - Hälso och sjukvårdsövergripande indikationer). In: Affairs MoHaS, ed. Stockholm: National Board on Health and Welfare; 2009.

[40] Sund-Levander M, Grodzinsky E. The challenge of infections in frail elderly: The story of Mr Nilsson. Clinical Medical Reviews and Case Reports (CMRCS). 2016 [Online publication 2015-08-26]. PMid: 26842844.

[41] Ivy AC. What is normal or normally? Q Bull NW Univ Med Sci. 1944; 18: 22-32. 